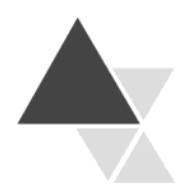

\title{
Avaliação da viabilidade de implementação das Boas Práticas em Unidades de Alimentação e Nutrição de Centros de Educação Infantil de Piracicaba, São Paulo
}

\author{
Elisa Medeiros Ravagnani ${ }^{1}$, Gilma Lucazechi Sturion ${ }^{2}$
}

O trabalho tem como objetivo avaliar o nível de adequação às Boas Práticas em Unidades de Alimentação e Nutrição (UAN) de centros educacionais infantis (CEI) municipais de Piracicaba (SP) visando subsidiar ações para a melhoria da eficácia do Programa e contribuir para a garantia da segurança dos alimentos oferecidos e a saúde das crianças assistidas. Nas UAN de dois CEI aplicou-se uma lista de verificação para avaliação das Boas Práticas, elaborada com base nos regulamentos técnicos. Realizou-se a contagem total de microrganismos aeróbios mesófilos e psicrotróficos, coliformes totais e fecais em duas preparações, consideradas de maior risco, distribuídas em cada CEI. A classificação das não conformidades observadas foi definida, de acordo com o grau de importância para a segurança dos alimentos. Concomitantemente foram identificados os investimentos requeridos para superação das mesmas. Constatou-se um nível insatisfatório médio de $64,3 \%$ de adequação às Boas Práticas. Dos itens não conformes, aproximadamente $45 \%$ evidenciaram a necessidade de medidas corretivas imediatas. As análises microbiológicas atestaram as deficiências no processo. Com base nas condições observadas, concluiu-se que é viável a implementação das Boas Práticas. Porém, recomenda-se a sensibilização dos dirigentes para otimizar os recursos disponíveis, visando a capacitação de manipuladores, e para a definição de recursos orçamentários a serem investidos especificamente para a eliminação das demais não conformidades.

Palavras - chave: centros educacionais infantis, unidades de alimentação e nutrição, segurança do alimento, boas práticas.

\section{Evaluation of the Viability to Implement Food Service Good Practices in Day Care Centers of Piracicaba, São Paulo}

The objective of this work is to evaluate the level of adequacy of good practices in food service in municipal day-care centers of Piracicaba (São Paulo,Brazil) in order to verify the viability to implement this tool in the Municipal Program of Feeding and Childhood Nutrition Units to guarantee food safety and the health of assisted children. In the food service of two day care centers an evaluation using a check list of good practices and microbiological analysis of two preparations previously selected was done. The non conformities observed were classified, in accordance with the degree of importance for the food safety and also an analysis of investments required in order to overcoming the non conformities. The level of non satisfactory adequacy of the good practices was $64.3 \%$ on average. About $45 \%$ of items problems safety problems concerning the meals offered. The results of the microbiological analysis had demonstrated deficiencies in the process. Based on the conditions found in the two units could be concluded that is viable the implementation of the good practices in the municipals day care centers. However the managers should be prepared to optimize the resources used for manipulation practices and to develop a budget prevision in the way to eliminate all others existing non conformities.

Key-words: day care centers, foodservice establishments, food safety, good practices.

\footnotetext{
${ }^{1}$ Mestre em Ciências, Escola Superior de Agricultura "Luiz de Queiroz" (ESALQ), USP.

${ }^{2}$ Professora Doutora, Escola Superior de Agricultura "Luiz de Queiroz" (ESALQ), USP. Endereço para correspondência: Av. Pádua Dias, 11. Piracicaba, SP. CEP: 13418 900. Tel.: (19) 34294150.E-mail: glsturio@esalq.usp.br
} 


\section{Introdução}

Os centros educacionais infantis (CEI) têm como finalidade o atendimento em educação de crianças menores de seis anos, contemplando as necessidades de desenvolvimento intelectual, bem como o direito à socialização, às vivências infantis e aos cuidados específicos. Têm, também, o compromisso de manter e promover a saúde e, nesse contexto, destaca-se a alimentação ${ }^{[1]}$. Para isso, os CEI contam com Unidades de Alimentação e Nutrição (UAN), cujos objetivos são contribuir para manter, melhorar ou recuperar a saúde dos usuários, por meio de uma alimentação balanceada nutricionalmente e inócua e, concomitantemente, com a adoção e consolidação de hábitos alimentares saudáveis ${ }^{[2]}$.

A criança usuária de CEI, pertence ao segmento etário que vai desde os quatro meses até seis anos de idade, fase que a predispõe a maior probabilidade de adquirir e desenvolver infecções, sobretudo as de repetição, como as de ordem respiratória, gastrintestinal e cutânea. O ambiente coletivo dessas instituições proporciona grande circulação e transmissão de agentes patogênicos ${ }^{[3,4]}$.

Os trabalhos científicos existentes mostram que as crianças usuárias dos centros educacionais infantis adoecem mais freqüentemente que aquelas cuidadas exclusivamente em casa ${ }^{[4,5]}$ e que o aumento da exposição aos agentes que causam agravos à saúde, constitui fator de risco ${ }^{[3]}$.

$\mathrm{O}$ fato das refeições realizadas durante o período de permanência no centro educacional, representar para as crianças de países em desenvolvimento, praticamente a única oportunidade ${ }^{[6]}$, para o acesso diário a nutrientes e energia, amplia a responsabilidade dos gestores, no sentido de não expor o público infantil a complicações causadas por diversas doenças, veiculadas por alimentos inseguros, que possam integrar as refeições.

Vico \& Laurenti ${ }^{[3]}$ estudaram a mortalidade de crianças usuárias de centros infantis e observaram um declínio de óbitos por gastroenterites, causadas principalmente por agentes transmitidos por contato oral/fecal ou por água e alimentos contaminados. Os mesmos autores enfatizam que os índices observados são inaceitáveis, considerando a existência de recursos conhecidos, simples e de baixo custo para a garantia da qualidade higiênico-sanitária desses serviços.

No Brasil, os dados sobre surtos de doenças transmitidas por alimentos (DTA) são ainda incipientes e a notificação encontra-se abaixo da ocorrência real [7]. Além disso, existem discrepâncias relativas às informações divulgadas pelos órgãos competentes da área. No estado de São Paulo, em 1999, segundo dados do Centro de Vigilância Sanitária (CVS), o maior número de surtos de DTA ocorreu em residências, seguido por panificadoras, supermercados e salões de festas. As informações do Centro de Vigilância Epidemiológica (CVE) para o mesmo ano apontam como principais locais de ocorrência desses episódios escolas, creches, seguidos por residências, restaurantes e similares ${ }^{[8]}$.

Levantamento realizado em 2004 e 2005, sobre doenças transmitidas por água e alimentos notificados pelo CVE da cidade de 
São Paulo revelou 83 e 86 surtos, respectivamente. Entre esses, 3 e 19 ocorreram em CEI ou seja, $3,6 \%$ e $22,1 \%$, respectivamente. Nos anos de 2002, 2003 e 2004, no CVE do município de Piracicaba, foram notificados 32,25 e 6 surtos, respectivamente, dos quais 17,25 e 2 , registrados em CEI. A redução observada pode ser decorrente de melhorias na qualidade do atendimento às crianças ou, em pior situação, motivada por dificuldades identificadas no sistema de notificação das DTA no município ${ }^{[9]}$.

$\mathrm{O}$ risco de ocorrência de surtos de toxinfecções alimentares em CEI pode ser grande, pois além dos problemas inerentes à deficiência nos processos produtivos, presentes em grande parte das UAN, demonstrados em diversos estudos, [7, 10, 11, 12] existe a vulnerabilidade do grupo assistido. As doenças transmitidas por alimentos (DTA) podem desencadear um quadro clínico leve, severo, ou até mesmo a morte, principalmente no caso de grupos de risco, como crianças, idosos e/ou pessoas imunodeprimidas ${ }^{[13]}$.

Os referidos surtos geralmente se desenvolvem por falhas múltiplas em uma ou mais etapas da produção, incluindo: refrigeração inadequada, contaminação cruzada, uso de produtos de origem desconhecida, não registrados nos órgãos competentes, higienização incorreta, manipuladores infectados/contaminados, preparo do alimento com amplo intervalo antes do consumo, processamento térmico insuficiente (cocção ou reaquecimento), conservação a quente imprópria e utilização de sobras não conservadas adequadamente ${ }^{[13]}$.
Dentre as causas mais comuns encontram-se a má utilização da temperatura no preparo e conservação dos alimentos. O binômio "tempo e temperatura" é considerado um fator determinante para controlar o número de microrganismos durante o processamento, manipulação e distribuição dos alimentos para consumo $^{[13]}$. De modo geral, as UAN recebem diariamente, em grande quantidade, alimentos de alta perecibilidade, que demandam tempo de estocagem, de manipulação e exposição, muitas vezes sob temperaturas inadequadas. Tais fatores favorecem a contaminação e multiplicação bacteriana no alimento que, se consumido, pode levar a uma toxinfecção alimentar.

Por isso, além de oferecer uma alimentação que atenda às necessidades nutricionais, os serviços de alimentação e nutrição infantil devem adotar métodos que avaliem a qualidade higiênico-sanitária das refeições servidas. Logo, a adoção de ferramentas que garantam a inocuidade e integridade dos alimentos oferecidos se torna imprescindível.

Os critérios de higiene e boas práticas operacionais para alimentos estão estabelecidos pelos órgãos regulatórios do País, destacando-se as resoluções elaboradas pela diretoria colegiada as RDC, da Agência Nacional de Vigilância Sanitária (ANVISA), emitidas pelo Ministério da Saúde (MS) a saber: RDC № $275^{\text {[14] }}$ de 21 de outubro de 2002, que contempla o roteiro básico para elaboração dos Procedimentos Operacionais Padronizados (POP) e lista de verificação (check list) das Boas Práticas de Fabricação (BPF) em estabelecimentos produtores ou industrializadores de alimentos; RDC № 216, 
de 15 de setembro de 2004, que estabelece os procedimentos de Boas Práticas para serviços de alimentação a fim de garantir a qualidade higiênico-sanitária e a conformidade dos alimentos com a legislação sanitária ${ }^{[15]}$. Destaca-se, também, a Portaria № 06 publicada em 10 de março de 1999, pelo Centro de Vigilância Sanitária (CVS) do Estado de São Paulo ${ }^{[16]}$ que estabelece os parâmetros e critérios para o controle higiênico-sanitário em estabelecimentos de alimentos.

Esse conjunto de regulamentos define, entre outros aspectos, que todos os estabelecimentos que manipulam alimentos devem dispor de Manual de Boas Práticas de Fabricação - MBP, Procedimentos Operacionais Padronizados - POP e manipuladores de alimentos, comprovadamente capacitados ${ }^{[14]}$.

É importante que as UAN, principalmente quando localizadas nos centros infantis, adotem os procedimentos regulamentares sobre as condições higiênicosanitárias para que as crianças tenham acesso a uma alimentação balanceada nutricionalmente e inócua e não sejam expostas às toxinfecções alimentares.

Assim, o objetivo do presente trabalho consistiu na avaliação do nível de adequação às Boas Práticas em Unidades de Alimentação e Nutrição (UAN) de centros educacionais infantis (CEI) municipais de Piracicaba (São Paulo) visando subsidiar ações para maior eficácia do Programa e contribuir para a garantia da segurança dos alimentos oferecidos e, concomitantemente, a saúde das crianças assistidas.

\section{Metodologia}

\section{Amostra}

Os 43 Centros Educacionais Infantis (CEI) municipais de Piracicaba atendem, aproximadamente, 1700 crianças e são subordinados à Secretaria Municipal de Educação. As Unidades de Alimentação e Nutrição dos centros têm o gerenciamento centralizado na Divisão de Alimentação e Nutrição (DAN) da referida Secretaria. Desta forma, observam-se em todas as unidades educacionais condições semelhantes quanto à estrutura e operacionalização do serviço.

O estudo foi realizado nos centros educacionais infantis municipais de Piracicaba integrantes da amostra da pesquisa "Contrastes regionais nos custos, qualidade e operacionalização do Programa Nacional de Alimentação Escolar - PNAE e seu impacto sobre os padrões alimentares da população brasileira" (Processo CNPq №. 50.4369/20032), a qual logrou aprovação (Processo №. 099/2004) pelo Comitê de Ética da Faculdade de Odontologia de Piracicaba (UNICAMP).

Para a definição dos CEI que integrariam a pesquisa, foi utilizada a amostra probabilística, ou seja, as unidades foram sorteadas de maneira que a probabilidade de um CEI ser incluído na amostra fosse proporcional ao número de crianças atendidas. Para essa etapa foram considerados todos os CEI mantidos no município pela prefeitura, por meio da secretaria da educação. Foi elaborada uma tabela, acumulando-se o número de alunos, de maneira que cada CEI foi associado a um intervalo de valores da freqüência acumulada de alunos. As duas unidades que integraram a amostra foram 
escolhidas, após contato com os responsáveis e, prévio consentimento dos mesmos, para a realização da pesquisa. Cabe registrar que os dois CEI selecionados foram escolhidos, respeitando a probabilidade em função do número de crianças e não a localização geográfica das mesmas.

O sorteio foi realizado, utilizando-se programa específico, desenvolvido por meio do software $S A S^{[17]}$.

Os centros educacionais infantis participantes da pesquisa foram aqui identificados como A e B. Quanto as UAN, o CEI A possuía uma unidade responsável pelas refeições da totalidade das crianças assistidas, enquanto o B contava com duas UAN, uma responsável pela preparação das refeições oferecidas às crianças vinculadas ao Programa de Berçário II e Maternal I e outra pelas refeições oferecidas aos matriculados dos Programas de Maternal II, Jardim I, Jardim II e Pré-escola. Assim, as UAN foram denominadas: UAN A, UAN B1 e UAN B2, respectivamente.

\section{Avaliação do nível de adequação às Boas Práticas em serviços de alimentação}

Uma lista de verificação foi aplicada nas UAN, visando à avaliação do nível de adequação às Boas Práticas. A referida lista foi elaborada tendo por base os regulamentos sanitários vigentes ${ }^{[14,15,16]}$ e o manual da Associação Brasileira de Refeições Coletivas ${ }^{[18]}$. A mesma contemplou os oito módulos relacionados, a seguir: 1. Edificações e instalações; 2. Equipamentos, móveis e utensílios; 3. Manipuladores; 4. Produção e transporte do alimento; 5. Fluxo de produção;
6. Higienização e processamento de alimentos; 7. Transporte de matéria-prima e/ou produto final; 8. Documentação e Registro. Cada um dos oito módulos contemplou os procedimentos que deveriam ser observados nas UAN. Para a observação dos procedimentos da lista de verificação e preenchimento da mesma, a rotina de trabalho diária de cada UAN foi acompanhada durante uma semana (5 dias consecutivos), entre o período das 7:00h às 17:00h.

\section{Análises microbiológicas}

Com o objetivo de complementar a avaliação das Boas Práticas, foram realizadas análises microbiológicas de duas preparações, consideradas de maior risco, distribuídas em cada CEI e selecionadas com base no tipo de matéria-prima e ingredientes, grau de manipulação, forma de distribuição, freqüência de consumo, pelas crianças, conforme o estágio de desenvolvimento.

De acordo com a descrição do fluxo operacional de cada preparação, foram definidos distintos pontos para coletas das amostras com o objetivo de avaliar a qualidade microbiológica da matéria-prima e o efeito da manipulação e tratamento térmico sobre as contagens do produto final. Cada preparação foi acompanhada duas vezes, em diferentes dias e semanas. Assim, em cada etapa, foram realizadas duas amostragens. A metodologia empregada para a coleta das amostras foi a proposta por Silva et al ${ }^{[19]}$. Os resultados foram analisados tendo por base o cálculo da média aritmética dos valores obtidos para duas amostras. Considerando o objetivo do trabalho, optou-se por adotar amostra indicativa das condições higiênico-sanitárias 
de acordo com a RDC № 12 de 02 de janeiro de 2001, expedida pela ANVISA/MS ${ }^{[20]}$, que aprova o regulamento técnico sobre padrões microbiológicos para alimentos.

$\mathrm{Na}$ UAN A analisou-se o "leite reconstituído", servido em mamadeiras, a partir de coleta de amostras da água do filtro da unidade, utilizada para reconstituição do leite em pó, do liquidificador após a higienização, usado para homogeneização da preparação, e do leite pronto para consumo. Selecionou-se, também para análise, nesta unidade a preparação "estrogonofe de frango", com a realização das coletas de amostras na etapa anterior à cocção, ou seja, do peito de frango cru temperado e da preparação pronta para o consumo.

Na UAN B analisou-se o "leite com achocolatado" com a coleta de amostras da água da torneira da unidade, utilizada para reconstituição do leite em pó, do liquidificador após a higienização, utilizado para homogeneização da preparação e do leite pronto para consumo. Nesta unidade, analisouse também a preparação "frango ao molho" a partir da coleta de amostras na etapa anterior a cocção, ou seja, do frango cru e da preparação pronta para o consumo.

seguintes microrganismos indicadores: contagem total de microrganismos mesófilos aeróbios no leite e psicrotróficos aeróbios nas carnes, pois são mantidas sob refrigeração, e coliformes totais e fecais para ambos. Para a água realizou-se a contagem de coliformes totais e fecais, preconizada pela Portaria № 518 de 25 de março de 2004, publicada pela ANVISA/MS, que estabelece os procedimentos e responsabilidades relativos ao controle da água para o consumo humano e seu padrão de potabilidade ${ }^{[21]}$.

\section{Contagem total de microrganismos aeróbios mesófilos e psicrotróficos}

Coletou-se $500 \mathrm{~g}$ ou $\mathrm{mL}$ de amostra de maneira asséptica como unidade de amostra. Destas $500 \mathrm{~g}$ ou $\mathrm{mL}, 25 \mathrm{~g}$ ou $\mathrm{mL}$ foi homogeneizada com $225 \mathrm{~mL}$ do diluente $(1: 10)$ e, a partir desta diluição inicial, foram realizadas as diluições decimais subseqüentes necessárias para se obter a contagem. Para suabe foi usada a técnica do esfregaço de superfície, em área delimitada de $25 \mathrm{~cm}^{2}$, adotando-se procedimento proposto por Silva ${ }^{[19]}$.

As amostras foram inoculadas em duplicata pelo método Pour Plate, acrescentando o meio de cultura ágar padrão para contagem, previamente fundido, resfriado a $45^{\circ} \mathrm{C}$. Após solidificação do meio, as placas foram invertidas e incubadas a $35^{\circ} \mathrm{C} / 48$ horas para contagem de mesófilos e a $7^{\circ} \mathrm{C} / 10$ dias para contagem de psicrotróficos. A contagem das colônias foi realizada nas placas com 25 a 250 colônias. $\mathrm{O}$ resultado foi expresso em unidade formadora de colônia (UFC)/g ou mL ${ }^{[19]}$.

\section{Contagem de coliformes totais e fecais}

Para preparação da amostra e diluições seriadas seguiu-se o procedimento descrito anteriormente.

$\mathrm{Na}$ inoculação foi utilizada a metodologia dos tubos múltiplos. Para a carne e preparações lácteas, empregou-se a série de três tubos sendo a primeira série com $20 \mathrm{~mL}$ de meio e $10 \mathrm{~mL}$ de amostra; 
segunda série com $10 \mathrm{~mL}$ de meio e $1 \mathrm{~mL}$ de amostra e terceira série com $10 \mathrm{~mL}$ de meio e $0,1 \mathrm{~mL}$ de amostra. A série de tubos com Caldo Lauril Sulfato Triptose (LST) com tubos de Durham invertidos, foi inoculada com as diluições e incubados a $35^{\circ} \mathrm{C} / 24$ 48h, com subseqüente observação do crescimento e produção de gás, segundo Silva et $a l^{[19]}$. Para a água foi utilizada série de cinco tubos.

Para confirmação dos coliformes totais transferiu-se dos tubos de LST positivos o inoculo com o auxílio de uma alça bacteriológica para tubos com Caldo Bile Verde Brilhante (VB), que foram incubados a $35^{\circ} \mathrm{C} / 24-48$ horas. Por fim, realizou-se a observação do crescimento e produção de gás e determinação do número mais provável (NMP)/g a partir da tabela de NMP ${ }^{[19]}$.

Para a confirmação da presença de coliformes fecais transferiu-se o inoculo dos tubos de LST positivos para tubos com EC, que foram incubados a $45^{\circ} \mathrm{C}$ por 24 a 48 horas, e conseqüente observação do crescimento e produção de gás e determinação do NMP na tabela ${ }^{[19]}$.

\section{Análise dos resultados da lista de verificação adotada}

Com base nos resultados da lista de verificação calculou-se $\mathrm{o}$ índice de não conformidades de cada UAN e de cada um dos oito módulos contemplados na referida lista. A influência de cada procedimento não conforme sobre o grau de risco em relação à inocuidade do alimento foi considerada para a classificação em: imprescindível (I), o procedimento crítico para a proteção contra surtos de DTA e que necessita de correção imediata; necessário $(\mathrm{N})$, o procedimento não conforme não essencial para o controle efetivo das doenças causadas por alimentos, mas que contribui para a ocorrência destas, podendo ser fornecido tempo maior para a adequação. Essa classificação é indicada para a elaboração de planos de metas para adequações, com foco nas prioridades ${ }^{[22,23]}$.

A adequação de um estabelecimento aos procedimentos preconizados por um sistema de qualidade requer investimentos em recursos financeiros e humanos. No caso de instituições públicas, onde geralmente os recursos são limitados, com base no referido critério de classificação dos procedimentos, poder-se-á orientar o emprego destes, considerando as prioridades de adequação e os prazos de implementação dos mesmos.

\section{Coleta de dados}

A coleta de dados foi liderada pela primeira autora da pesquisa, que contou com equipe previamente treinada e formada por graduandos do Curso de Ciências dos Alimentos (ESALQ, USP - Campus de Piracicaba).

\section{Resultados e Discussão}

Vinculadas a Secretaria Municipal de Educação, as Unidades de Alimentação e Nutrição têm o gerenciamento centralizado na Divisão de Alimentação e Nutrição (DAN). O Programa dispunha, para cada criança matriculada, na época da coleta de dados, de R\$ 0,22, por dia letivo. Esse valor, repassado pelo Governo Federal, representava $6 \%$ do dispêndio total do município com o Programa que continua sendo acompanhado pelo 
Conselho Municipal de Alimentação Escolar CAE e tem seu planejamento e supervisão, assumidos por profissionais capacitados. Cardápios diferenciados são elaborados para cada estágio de vida (alunos matriculados nos programas de berçário, maternal, jardim e préescola). Com exceção do cardápio do lactário, que reúne 5 refeições diárias, os demais cardápios são compostos por 4 refeições (entrada, almoço, intervalo e final da jornada) durante 250 dias no ano. Nas UAN atuam manipuladores, que recebem treinamentos (anuais) e integram o quadro de funcionários públicos municipais e ainda, aqueles contratados por meio de empresas que prestam serviços terceirizados.

\section{Avaliação do nível de adequação às Boas Práticas}

O percentual médio de não conformidades para as três UAN foi de $35,7 \%$.

A UAN A apresentou 35,7\% de procedimentos não conformes, a UAN B1, $37,7 \%$ e a UAN B2 33,7\%, sendo que destes, a aplicação de ações corretivas é imprescindível em 44,5\% (em média).

A ANVISA classifica o atendimento dos procedimentos definidos pela legislação sanitária em três grupos: grupo I com $76 \%$ a $100 \%$ de atendimento, grupo II, com $51 \%$ a $75 \%$ e grupo III, com até $30 \%{ }^{[14]}$. De acordo com a classificação, as UAN A, B1 e B2 integram o grupo II, por atenderem $64,3 \%$, $62,3 \%$ e $66,3 \%$, respectivamente. Considerando o enquadramento no Grupo I a classificação observada indica a necessidade de adequação das UAN quanto aos procedimentos não conformes.

Na pesquisa de Akutsu ${ }^{[11]}$, do total de 10 UAN analisadas, $80 \%$ foram classificadas no grupo I e $20 \%$ no grupo II, sendo os resultados obtidos pelos autores, mais satisfatórios que os obtidos pela presente pesquisa.

A Figura 1 mostra a distribuição de não conformidades por módulo da lista de verificação de acordo com as UAN (A, B1 e B2). Os resultados revelam percentuais similares ou até iguais que podem ser explicados, em parte, pelo modelo de gerenciamento que é centralizado e, portanto, definido para todas as UAN, especialmente no tocante às condições operacionais padronizadas, aos recursos humanos e a infra estrutura. 
Figura 1 - Distribuição percentual de não conformidades de acordo com o módulo e a UAN. Piracicaba, 2005

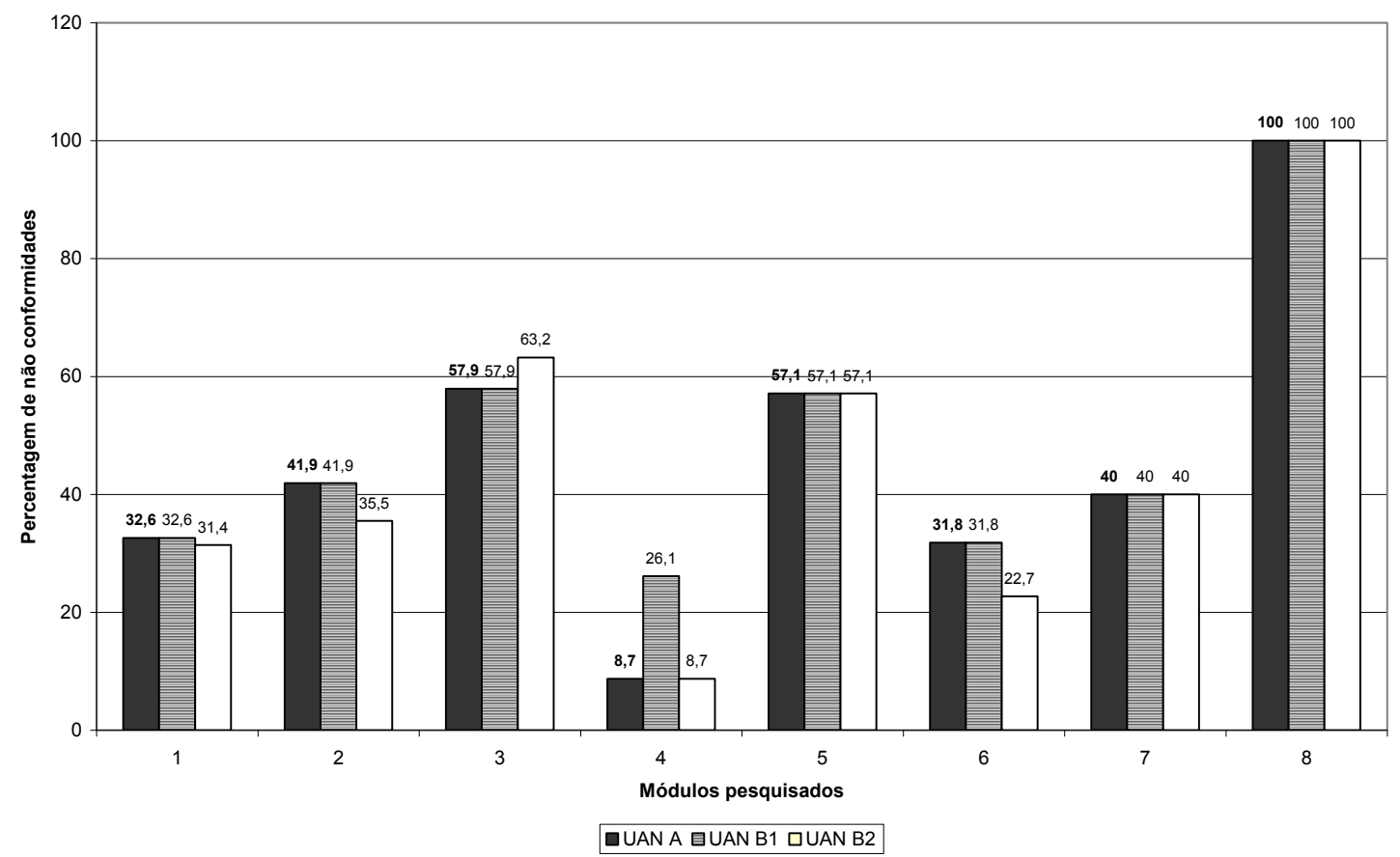

1- Edificações e instalações

2- Equipamentos, móveis e utensílios

3- Manipuladores

4- Produção e transporte do alimento
5- Fluxo de produção

6- Higienização e processamento dos alimentos

7- Transporte matérias-primas e/ou produto final

8- Documentação e registro
Os módulos que apresentaram proporções (médias) de não conformidades mais elevadas foram: 8-Documentação e Registro (100\%). 3 - Manipuladores (57,9\%), 5 - Fluxo de produção $(57,1 \%)$ e 7 Transporte de matérias-primas (40\%). Além disso, nos módulos Manipuladores, Fluxo de produção e Transporte de matérias-primas, as percentagens de não conformidades, cuja ação corretiva imediata foi considerada imprescindível (I), foram as mais expressivas, sendo $73,9 \%, 100 \%$ e $100 \%$, respectivamente. Nos módulos 6 - Higienização e processamento e 4 - Produção e transporte, apesar das menores proporções de não conformidades, foram identificados índices de procedimentos (I) também elevados, 82,9\% e $69 \%$, respectivamente.

O Quadro 1 apresenta os procedimentos não conformes (I), ou seja, aqueles diretamente relacionados aos entraves à segurança do alimento. 
Quadro 1. Procedimentos não conformes classificados como imprescindíveis* observados nas UAN integrantes da pesquisa. Piracicaba, 2005

\begin{tabular}{|c|c|}
\hline Módulos observados & Procedimentos não conformes \\
\hline $\begin{array}{l}\text { Equipamentos, móveis } \\
\text { e utensílios }\end{array}$ & $\begin{array}{l}\text { - insuficiência de equipamentos para conservação a quente; } \\
\text { - inexistência de controle de temperatura; } \\
\text { - inexistência de responsável comprovadamente capacitado para } \\
\text { higienização; } \\
\text { - utilização de utensílio de material contaminante (madeira). }\end{array}$ \\
\hline Manipuladores & $\begin{array}{l}\text { - lavagem e assepsia das mãos não realizadas de acordo com a técnica } \\
\text { e freqüência adequada; inexistência de instruções sobre esse } \\
\text { procedimento afixado no local; } \\
\text { - inexistência de programa de capacitação e supervisão dos } \\
\text { manipuladores; } \\
\text { - visitantes não paramentados na área de manipulação. }\end{array}$ \\
\hline $\begin{array}{l}\text { Produção e transporte } \\
\text { dos alimentos }\end{array}$ & $\begin{array}{l}\text { - operações de recepção da matéria-prima e ingredientes não realizadas } \\
\text { em local protegido e isolado da área de processamento; } \\
\text { - inexistência de medições de temperatura no recebimento de } \\
\text { alimentos perecíveis; } \\
\text { - existência de produtos não perecíveis com validade vencida. }\end{array}$ \\
\hline Fluxo de produção & $\begin{array}{l}\text { - fluxo não linear; } \\
\text { - inexistência de barreira física ou técnica na área de pré-preparo e } \\
\text { preparo e de controle da circulação e acesso de pessoal; } \\
\text { - fornecedores qualificados não monitorados constantemente. }\end{array}$ \\
\hline $\begin{array}{l}\text { Higienização e } \\
\text { processamento dos } \\
\text { alimentos }\end{array}$ & $\begin{array}{l}\text { - descongelamento realizado sob temperatura ambiente; } \\
\text { - legumes, verduras e frutas consumidas com casca ou cruas não } \\
\text { higienizados com a técnica e freqüência adequada; } \\
\text { - tempo de espera, entre o final da produção da preparação e a } \\
\text { distribuição, prolongado (acima de } 1 \text { hora), com exposição do mesmo } \\
\text { à faixa de temperatura de risco (abaixo de } 60^{\circ} \mathrm{C} \text { ). }\end{array}$ \\
\hline
\end{tabular}

* Procedimento que necessita correção imediata.

Akutsu et al ${ }^{[11]}$, Trindade ${ }^{[12]} \mathrm{e}$ Pereira ${ }^{[7]}$ também observaram em UAN, elevadas proporções (entre 35 e 50\%) de não conformidades para os módulos descritos na presente pesquisa, demonstrando as similaridades deste tipo de serviço entre as mesmas.

Shojaei et al ${ }^{[24]}$ realizaram contagem de microrganismos de origem fecal em mãos de manipuladores de alimentos e constataram, em um primeiro momento, contaminação de 72,7\% dos integrantes do grupo. Observaram também que esta contaminação decresceu para $32 \%$, após adoção de instruções para os manipuladores, envolvendo procedimentos de higienização das mãos e sua importância para a redução da mesma. Esse resultado demonstra que o treinamento dos manipuladores é uma ação eficaz e de baixo custo para o alcance desta conformidade. É importante lembrar que a incorreta higienização das mãos concorre para que os manipuladores se tornem uma fonte potencial de contaminação de bactérias patogênicas ${ }^{[13]}$.

As verduras, os legumes e frutas consumidos com casca ou crus devem ser higienizados segundo as etapas: lavagem com água potável; desinfecção a partir da imersão em solução clorada entre 100 e $250 \mathrm{mg} / \mathrm{L}$ e enxágüe em água potável ${ }^{[16]}$. Os procedimentos adotados nas UAN não contemplavam adequadamente a etapa de sanitização com 
destaque para o emprego da concentração dos produtos químicos, tempo de contato, relação produto e solução clorada.

Segundo Silva ${ }^{[13]}$, o binômio "tempo e temperatura" consiste no fator determinante para controlar o número de microrganismos durante o processamento, manipulação e distribuição dos alimentos. Como regra geral os alimentos cozidos devem atingir uma temperatura interna mínima de $74^{\circ} \mathrm{C}$ ou combinações como $65^{\circ} \mathrm{C}$ por 15 minutos ou $70^{\circ} \mathrm{C}$ por 2 minutos, para garantir a destruição das células vegetativas. Após o procedimento, o alimento deve ser mantido em temperaturas superiores a $55^{\circ} \mathrm{C}$, a fim de impedir a proliferação de sobreviventes e germinação dos $\operatorname{esporos}^{[13,16]}$.

\section{Análises microbiológicas}

A Tabela 1 reúne os resultados obtidos por meio das análises microbiológicas.

Tabela 1 - Contagem total de microrganismos mesófilos/psicrotróficos aeróbios e NMP de coliformes totais e fecais em preparações servidas nas UAN A e B. Piracicaba, 2005

\begin{tabular}{|c|c|c|c|c|c|c|}
\hline & \multirow{2}{*}{ Preparação } & \multirow{2}{*}{ Etapas } & \multicolumn{2}{|c|}{$\begin{array}{l}\text { Contagem microrganismos } \\
\text { aeróbios (UFC/g) }\end{array}$} & \multicolumn{2}{|c|}{$\begin{array}{c}\text { Contagem coliformes } \\
\text { (NMP/g) }\end{array}$} \\
\hline & & & & Psicrotróficos & Totais & Fecais \\
\hline \multirow{5}{*}{$\begin{array}{l}\text { UAN } \\
\text { A }\end{array}$} & \multirow{3}{*}{$\begin{array}{l}\text { Leite } \\
\text { reconstituído }\end{array}$} & Água & Não realizado & Não realizado & 92 & 0,5 \\
\hline & & $\begin{array}{l}\text { Liquidificador } \\
\text { após } \\
\text { higienização }\end{array}$ & $2,7 \times 10^{3}$ & - & $\geq 240$ & $<3$ \\
\hline & & Leite pronto & $8,5 \times 10$ & - & $<3$ & $<3$ \\
\hline & \multirow{2}{*}{$\begin{array}{c}\text { Estrogonofe } \\
\text { de frango }\end{array}$} & $\begin{array}{l}\text { Frango cru } \\
\text { temperado }\end{array}$ & - & $5,4 \times 10^{4}$ & $4,6 \times 10^{2}$ & $<3$ \\
\hline & & $\begin{array}{l}\text { Estrogonofe } \\
\text { pronto }\end{array}$ & - & $<0,1 \times 10$ & $<3$ & $<3$ \\
\hline \multirow{5}{*}{$\begin{array}{c}\text { UAN } \\
\text { B }\end{array}$} & \multirow{3}{*}{$\begin{array}{l}\text { Leite com } \\
\text { achocolatado }\end{array}$} & Água & Não realizado & Não realizado & $<3$ & $<3$ \\
\hline & & $\begin{array}{l}\text { Liquidificador } \\
\text { após } \\
\text { higienização } \\
\end{array}$ & $3,1 \times 10^{3}$ & - & $\geq 240$ & $<3$ \\
\hline & & Leite pronto & $5,3 \times 10^{2}$ & - & $<3$ & $<3$ \\
\hline & \multirow{2}{*}{$\begin{array}{l}\text { Frango ao } \\
\text { molho }\end{array}$} & Frango cru & - & $3,2 \times 10^{3}$ & 9 & $<3$ \\
\hline & & Frango pronto & - & $8,0 \times 10$ & $<3$ & $<3$ \\
\hline
\end{tabular}


A Tabela 1 mostra que para o "leite reconstituído" servido em mamadeiras na UAN A, a água utilizada (reconstituição do leite em pó) não atende aos padrões legais vigentes, pois apresentou $92 \mathrm{NMP} / \mathrm{mL}$ de coliformes totais e $0,5 \mathrm{NMP} / \mathrm{mL}$ de coliformes fecais. De acordo com Portaria № $518^{[21]}$ a água para o consumo humano deve apresentar ausência em $100 \mathrm{~mL}$ de coliformes termotolerantes ou fecais. Além disso, a RDC № $12^{[20]}$ estabelece que a água envasada para o preparo de mamadeiras deve ser livre de coliformes, a $35^{\circ} \mathrm{C} / 100 \mathrm{~mL}$ (totais).

Picoli et al ${ }^{[25]}$ analisaram a água, proveniente de poço artesiano, utilizada em estabelecimento produtor de alimentos e obtiveram contagens médias de $1,3.10^{2}$ UFC/100 mL de coliformes totais e 10 UFC/100 mL de coliformes fecais. Os autores evidenciam a necessidade do controle sanitário da água, conforme estabelecido pelas boas práticas, que incluem a higienização semestral do reservatório e filtro, atestado anual de potabilidade e troca do elemento filtrante.

A contagem obtida de coliformes fecais para o liquidificador foi inferior ao limite de detecção ${ }^{[20]}$. Porém, a contagem total e de coliformes totais, que constituem um indicador dos níveis de higiene, foram elevadas, indicando deficiência da técnica de higienização do equipamento. Souza \& Campos ${ }^{[26]}$ encontraram coliformes fecais em $100 \%$ dos equipamentos amostrados em uma cozinha hospitalar. Os resultados evidenciaram a importância do treinamento dos manipuladores quanto à adequada execução da higienização dos equipamentos, pois de acordo com publicação ${ }^{[18]}$, equipamentos e utensílios devem ser totalmente livres de indicadores de contaminação fecal.

Enterobacter sakazakii é uma bactéria patogênica emergente, classificada pela International Commission on Microbiological Specifications for Foods (ICMSF) como "de risco severo para população restrita, representando ameaça de morte ou de seqüelas crônicas de longa duração”. As crianças de até um ano, particularmente os prematuros e os recém nascidos com baixo peso corporal são considerados grupos de risco. O veículo mais comum de contaminação bacteriana dos frascos e utensílios utilizados na preparação das mamadeiras têm sido fórmulas infantis em pó, uma vez que podem acumular-se nos mesmos facilitando a disseminação da bactéria. Uma maior incidência de $E$. sakasakii (24,24\% das amostras) em fórmulas infantis em pó para crianças, com idade entre 6 meses e 1 ano de idade foi observada, em relação às fórmulas para prematuros, recém-nascidos de até 6 meses de idade ${ }^{[27]}$.

As contagens realizadas no leite pronto demonstraram que o tratamento térmico, foi suficiente para mantê-lo em conformidade com os padrões estabelecidos pela legislação vigente ${ }^{[20]}$ (ausência de coliformes fecais e máximo $10 \mathrm{NMP} / \mathrm{ml}$ de coliformes totais) e obtenção de um produto final classificado como seguro. Contudo, além da amostra ser indicativa e não representativa, as condições observadas durante a preparação associadas às Boas Práticas não são ideais. Ilustra tal condição, o resfriamento realizado à temperatura ambiente. Assim, contaminações e proliferação de microrganismos podem ocorrer e o produto final representar um perigo para o público atendido. 
Salles \& Goulart ${ }^{[28]}$ relataram altos índices de coliformes fecais em preparações lácteas produzidas em lactários de hospitais do município de Florianópolis (Santa Catarina), comprovando a ineficiência ou ausência de um sistema de qualidade que garanta a segurança do alimento. Pessoa et al ${ }^{[29]}$ analisando preparações lácteas (município de São Paulo), constataram a presença de E. coli em 15,8\% das amostras. Santos ${ }^{[27]}$, também identificou elevados índices de coliformes totais $\mathrm{e}$ mesófilos aeróbios totais $\left(10^{3} \mathrm{NMP} / \mathrm{mL}\right.$ e $10^{4}$ UFC/g, respectivamente) em amostras de leite em pó reconstituído. Esses estudos mostram a prevalência de contaminação nesse tipo de preparação específica destinadas às crianças com menor idade.

Conforme registrado na Tabela 1 , na análise da preparação "estrogonofe de frango" servido na UAN A, o resultado encontrado para o frango cru cortado (matéria prima da preparação) e temperado foi $5,4.10^{4} \mathrm{UFC} / \mathrm{g}$ para contagem total de microrganismos

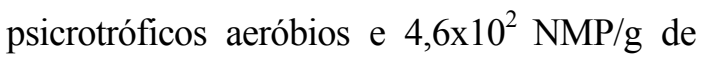
coliformes totais. Assim, a matéria-prima utilizada atendeu aos padrões estabelecidos pela legislação vigente (limite máximo de $10^{4}$ coliformes a $45^{\circ} \mathrm{C} / \mathrm{g}$ ou fecais) ${ }^{[19]}$. O tratamento térmico reduziu a contaminação, inicialmente observada, para valores inferiores ao limite de detecção, portanto, em conformidade com os padrões legais vigentes (limite máximo para produtos cárneos cozidos é $10^{3}$ coliformes a $\left.45^{\circ} \mathrm{C} / \mathrm{g}\right)^{[19]}$.

Na UAN B, para a preparação "leite com achocolatado", os resultados obtidos por meio da análise indicativa da água revelam que a mesma, por apresentar valores de coliformes totais e fecais inferiores ao limite de detecção, atendeu aos padrões microbiológicos, definidos pela Portaria № $518^{\text {[21] }}$ para potabilidade humana. Esse resultado difere daquele constatado por meio da análise da água integrante da preparação láctea, utilizada na UAN A. Mesmo se tratando de amostra indicativa, deve-se ressaltar que a água que abastece as UAN advém da mesma rede pública. Desse modo, a diferença na qualidade da água pode ser explicada por outras possíveis fontes de contaminação, tais como o reservatório de água ou o filtro, de onde é retirada a água para a preparação da mistura láctea da UAN A.

$\mathrm{Na}$ análise do suabe do liquidificador utilizado na homogeneização da mistura láctea a contagem de microrganismos aeróbios mesófilos e de coliformes totais, que constituem um indicador de higiene, foram igualmente elevados, como aquela observada na UAN A (Tabela 1), indicando também deficiência na higienização. De forma similar ao presente estudo, Pinto ${ }^{[30]}$ analisou equipamentos utilizados na produção de alimentos e detectou coliformes totais e fecais em $83,3 \%$ e $45,8 \%$, respectivamente. O autor registra que mesmo após a higienização, os equipamentos mantiveram expressivas porcentagens de coliformes totais $(72,7 \%)$ e fecais $(36,4 \%)$. Tomich et al ${ }^{[23]}$ observaram que mesmo após a higienização dos equipamentos, para algumas amostras, foi identificada elevação da contagem de bactérias mesófilas. Estes resultados mostraram a ineficiência do processo de higienização adotado.

A higienização de equipamentos pode evitar o risco de recontaminação dos alimentos durante todas as etapas do processo. Porém, se 
esta não é realizada adequadamente, o processo torna-se ineficaz e pode causar a contaminação cruzada, responsável por diversos surtos, como aqueles ocorridos nos Estados Unidos e Inglaterra ${ }^{[13]}$.

O leite com achocolatado na UAN B apresentou contagens abaixo do limite de detecção para coliformes e 5,3.10² UFC/ml na contagem global, atendendo aos padrões estabelecidos pela legislação (ausência coliformes fecais e máximo $10 \mathrm{NMP} / \mathrm{ml}$ de coliformes totais) ${ }^{[13]}$.

Ainda de acordo com a Tabela 1, a contagem total de bactérias no frango cru temperado, utilizado na preparação do "frango ao molho" na UAN B foi de $10^{3}$, enquanto que a de coliformes fecais apresentou-se inferior ao limite de detecção ${ }^{[20]}\left(10^{4}\right.$ coliformes a $\left.45^{\circ} \mathrm{C} / \mathrm{g}\right)$. O tratamento térmico reduziu consideravelmente ( 3 ciclos $\log$ ) a contagem de bactérias totais presentes (Tabela 1). A contagem de coliformes fecais se manteve inferior ao limite de detecção ${ }^{[20]}$.

Panisello et al ${ }^{[31]}$ avaliaram a ocorrência de doenças transmitidas por alimentos na Inglaterra e observaram que a carne de aves constituiu o principal veículo de transmissão de patógenos, sendo a Salmonella spp. o principal agente etiológico responsável pelos casos notificados. Os mesmos autores destacam a importância no controle de cada etapa do processamento desses alimentos (da aquisição da matéria-prima até o consumo) a fim de evitar a multiplicação de microrganismos patógenos eventualmente presentes.

\section{Adequação de não conformidades}

A proporção média de não conformidades observadas nas UAN foi de $35,7 \%$ e, em 44,5\% dessas, a aplicação de ações corretivas foi considerada imprescindível para assegurar a inocuidade do alimento. Deve-se lembrar da necessidade dos estabelecimentos atenderem no mínimo a $80 \%$ dos procedimentos, passando, assim, do grupo II para o grupo I, situação desejável para esse tipo serviço.

Destaca-se que, da totalidade dos procedimentos com prioridade de adequação, $73,5 \%$ requerem investimentos de recursos financeiros, com destaque para:

- instalação de telas milimétricas, medidores de temperaturas nos equipamentos e portas de acesso à área de armazenamento independente da área de manipulação;

- aquisição de saneantes, lixeiras com acionamento não manual, termômetros para registro de temperatura dos alimentos e de equipamentos de armazenamento a frio e balcões térmicos para distribuição das refeições;

- contratação de funcionários para viabilizar a supervisão constante das UAN e dos fornecedores assim como avaliar a implementação das Boas Práticas;

- estabelecimento de manutenção preventiva dos equipamentos;

- implementação de um programa de capacitação e treinamento dos manipuladores.

Merece destaque a necessária capacitação e treinamento dos manipuladores, 
notadamente quanto aos procedimentos relacionados à higiene, contaminação cruzada e controle do tempo e temperatura durante o fluxo operacional. Essa ação corretiva, desde que sistematizada, pode ser realizada pelos técnicos especializados da própria instituição, ou a partir de parcerias como, por exemplo, com universidades e institutos de pesquisa. Destaca-se que, no caso da não terceirização do referido treinamento, deve-se contabilizar como custos adicionais, o tempo necessário para planejamento e execução desta atividade e a participação dos manipuladores. Um programa de capacitação deve respeitar a periodicidade prevista, além da necessidade de constante monitoramento das atividades para avaliação da eficácia do mesmo ${ }^{[32]}$.

A maior dificuldade na implementação das Boas Práticas em CEI municipais é representada pela necessidade de investimentos, visto que, a disponibilidade de recursos financeiros para essa modalidade de intervenção é limitada. Alternativas tais como subsídios das instituições privadas do município por meio de seus programas de apoio a projetos sociais, podem contribuir para a eliminação do problema. O Programa também pode contar com o apoio das Universidades sediadas no município, no sentido de contribuir para a capacitação e treinamento da equipe técnica e manipuladores.

\section{Conclusão}

Pode-se concluir que, embora as Boas Práticas ainda não estivessem integralmente implantadas na época da obtenção dos dados, expressiva parcela dos procedimentos já era adotada. Além disso, conforme observado, um conjunto substancial das não conformidades pode ser corrigido por meio de treinamento e capacitação dos manipuladores, utilizando-se, por exemplo, recursos disponíveis no local.

Por outro lado as "não conformidades" observadas e também confirmadas pelos resultados das análises microbiológicas e ainda, por representarem entraves à segurança dos alimentos, reforçam a necessidade da adoção de ações corretivas imediatas.

$$
\text { Considerando as condições }
$$

observadas nas UAN, e o fato de representarem, de modo geral, as condições das demais existentes no município, concluise, também, que a implementação das Boas Práticas deverá ocorrer em curto prazo, mediante investimentos financeiros que devem ser contemplados nas previsões orçamentárias da instituição. Para tanto é necessária a sensibilização dos dirigentes responsáveis pela alocação dos recursos municipais.

Recomenda-se a continuidade do estudo no sentido de definir parâmetros que subsidiem a implementação de outros sistemas de garantia da qualidade higiênico-sanitária como, por exemplo, a Análise de Perigos e Pontos Críticos de Controle (APPCC), recomendado, principalmente, para estabelecimentos que atendem crianças em idade pré - escolar.

Agradecimentos: ao Conselho Nacional de Desenvolvimento Científico e Tecnológico CNPq, pelo apoio financeiro e ao Prof. Dr. Ernani Porto (ESALQ/USP) pela colaboração nas análises microbiológicas. 


\section{Referências Bibliográficas}

[1] Veríssimo MLOR.; Fonseca, RMGS. O cuidado da criança segundo trabalhadoras de creches. Revista Latino Americana de Enfermagem, Ribeirão Preto, v. 11, n. 1, p. 2835, 2003.

[2] Gandra, YR.; Gambardella, AMD. Avaliação de serviços de nutrição e alimentação. São Paulo: Sarvier, 1986. 113 p.

[3] Vico, ESR, Laurenti R. Mortalidade de crianças usuárias de creches no Município de São Paulo. Revista de Saúde Pública. 2004; 38(1): 38-44.

[4] Barros AJ. Child care attendance and common morbidity: Evidence of association in the literature and design issues. Revista de Saúde Pública, São Paulo, v. 33, n. 1, p. 98 106, fev.1999.

[5] Haskins, R.; Kotch, J. Day care and illness: Evidence, cost, and public policy. Pediatrics, El Grove Village, v. 77, n. 6, p. 951-982, Jun. 1986.

[6] Moreira, CVLde; Lordelo, REda. Creche em ambiente urbano pobre: ressonâncias no ecossistema desenvolvimental. Interação em Psicologia, Curitiba, v. 6, n. 1, p.19-30, jan./jun.2002.

[7] Pereira CHC. Avaliação das unidades de alimentação e nutrição da cidade de Franca visando a promoção de saúde [dissertação]. Franca: Universidade de Franca; 2006.

[8] Passos MHC. Investigação de surtos de doenças transmitidas por alimentos. Campinas. Curso da Secretaria do Estado de São Paulo. Direção Regional de Saúde de Campinas; 2001.

[9] São Paulo (Estado). Secretaria da Saúde. Centro de Vigilância Epidemiológica. Divisão de doenças de transmissão hídrica e alimentar. Disponível em: $<$ http://www.cve.saude.sp.gov.br $>$. Acesso em: 05 mar. 2007
[10] Almeida, GD.; Jorge, IMG.; Gabriel, FL ; et al. Produção de refeições e creche: recursos para implementação das boas práticas de higiene e manipulação de alimentos, em busca de qualidade. Higiene Alimentar, São Paulo, v. 16, n. 94, p. 26-29, mar. 2002

[11] Akutsu, RC.; Botelho, RA.; CAMARGO, E.B.; Sávio, KEO.; Araújo, WC. Adequacy of good manufacturing procedures in foodservice establishments. Revista de Nutrição, Campinas, v. 18, n. 3, p. 419-427, maio/jun., 2005.

[12] Trindade, AA Subsídios para implementação do sistema de Análise de Perigos e Pontos Críticos de Controle em lactário. 2006. 119 p. Dissertação (Mestrado em Ciência e Tecnologia de Alimentos) - Escola Superior de Agricultura Luiz de Queiroz, Universidade de São Paulo, Piracicaba, 2006.

[13] Silva Junior, E.A. da. Manual de Controle Higiênico-Sanitário em serviços de alimentação. São Paulo: Varela; 2005.

[14] Brasil. Ministério da Saúde. Agência Nacional de Vigilância Sanitária. Portaria № 275, de 21 de outubro de 2002. Regulamento Técnico de Procedimentos Operacionais Padronizados aplicados aos Estabelecimentos Produtores/ Industrializadores de Alimentos. Brasília, 2002.

[15] Brasil. Ministério da Saúde. Agência Nacional de Vigilância Sanitária. Resolução RDC № 216 de 15 de setembro de 2004. Regulamento Técnico de Boas Práticas para Serviços de Alimentação. Brasília, 2004.

[16] São Paulo. Secretaria de Saúde. Portaria CVS № 6 de 10 de março de 1999. Regulamento técnico que estabelece os parâmetros e critérios para controle higiênicosanitário em estabelecimento de alimentos. São Paulo,1999.

[17] SAS INSTITUTE INC. The Statistical Analisys System (software). Versão 8.2. Cary, 2000.

[18] Associação Brasileira das Empresas de Refeições Coletivas. Manual ABERC de 
práticas de elaboração e serviço de refeições para coletividades. São Paulo; 2003.

[19] Silva N; Junqueira VCA, Silveira NFA. Manual de Métodos de Análise Microbiológica de Alimentos. São Paulo: Varela; 2001.

[20] Brasil. Ministério da Saúde. Agência Nacional de Vigilância Sanitária. ResoluçãoRDC № 12, de 02 de janeiro de 2001. Regulamento Técnico sobre Padrões Microbiológicos para Alimentos. Brasília, 2001.

[21] Brasil. Ministério da Saúde. Agência Nacional de Vigilância Sanitária. Portaria № 518, de 25 de março de 2004. Regulamento Técnico que Estabelece os procedimentos e responsabilidade relativos ao controle $\mathrm{e}$ vigilância da qualidade da água para consumo humano e seu padrão de potabilidade. Brasília, 2004

[22] Bryan FL. Prevention of foodborne diseases in food service establishments. Journal of environmental health. 1979; 41(4) : 198-206.

[23] Tomich RGP, Tomich TR, Amaral CAA, Junqueira RG, Pereira AJG. Metodologia para avaliação das Boas Práticas de Fabricação em indústrias de pão de queijo. Ciência e Tecnologia de Alimentos. 2005; 25(1): 115120.

[24] Shojaei H, Shooshtaripoor J, Amiri M. Efficacy of simple hand-washing in reduction of microbial hand contamination of Iranian. Food Research International. 2006; 39(5): 525529.

[25] Picoli SU, Bessa MC, Castagna SMF, Gottardi CPT, Schmidt V, Cardoso M. Enumeration of coliforms, Staphylococcus aureus and aerobic mesofilic bacteria throughout the manufacture process of a goat unripened cheese produced in a dairy plant. Ciência e Tecnologia de Alimentos. 2006; 26(1) : 64-69.

[26] Souza CL, Campos GD. Condições higiênico-sanitárias de uma dieta hospitalar. Revista de Nutrição. 2003; 16(1) : 127-134.
[27] Santos RFS dos. Ocorrência de Enterobacter sakazakii em fórmulas infantis para lactentes em hospitais e maternidades da região de Campinas/SP [dissertação]. Campinas: Universidade Estadual de Campinas; 2006.

[28] Salles RK, Goulart R. Diagnóstico das condições higiênico-sanitárias e microbiológicas de lactários hospitalares. Revista de Saúde Pública. 1997; 31(2) : 131139.

[29] Pessoa GVA, Calzada CT, Peixoto ES, Melles CEA, Kana E, Raskin M, Simonsen V, Irino K. Ocorrência de bactérias enteropatogênicas em São Paulo no septênio 1970 - 1976. III Sorotipos Shigella e Escherichia coli de gastroenterite infantil. Revista do Instituto Adolfo Lutz. 1978; 38(2) : 129-139.

[30] Pinto RG Avaliação microbiológica dos utensílios e equipamentos de uma indústria de pão de queijo [dissertação]. Belo Horizonte: Universidade Federal de Minas Gerais; 2001

[31] Panisello PJ, Rooney R, Quantick PC, Smith RS. Application of foodborne disease outbreak data in the development and maintenance of HACCP systems. International Journal of Food Microbiology. 2000; 59(3) : 221-234.

[32] Germano, Maria Isabel Simões. Treinamento de manipuladores de alimentos: fator de segurança alimentar e promoção da saúde. São Paulo: Varela. 2003. 165p. 